Arq. Bras. Med. Vet. Zootec., v.70, n.2, p.463-468, 2018

\title{
Tubulopapillary rectal adenocarcinoma in dog: clinical, surgical, pathological and immunophenotypical aspects: case report
}

\author{
[Adenocarcinoma retal tubulopapilar em cão: descrição clínica, cirúrgica, anátomo-patológica \\ e imunofenotípica: relato de caso] \\ A.R. Oliveira ${ }^{1}$, M.C. Flecher ${ }^{1}$, R.S. Horta ${ }^{1}$, M.C.C. Souza ${ }^{1}$, I. Hardt ${ }^{2}$, A.B.B. Gonçalves ${ }^{3}$, \\ G.D. Cassali $^{3}$, T.D. Souza ${ }^{1}$ \\ ${ }^{1}$ Universidade Vila Velha - Vila Velha - ES \\ ${ }^{2}$ Universidade Estadual Paulista Júlio de Mesquita Filho - Jaboticabal, SP \\ ${ }^{3}$ Universidade Federal de Minas Gerais - Belo Horizonte, MG
}

\begin{abstract}
Intestinal carcinomas are rare in dogs. The prognosis and survival time are dependent of the histological type, the invasion of the intestinal wall by the malignant cells and the ability of primary neoplasm to produce metastasis. This study reports a case of a Yorkshire dog that developed a rectal tubulopapillary adenocarcinoma progressing to a peritoneal carcinomatosis and multiple metastasis in large intestines, bladder, kidney, iliac lymph node, liver and lungs, six months after transanal surgical resection of the primary rectal neoplasm. Clinical, surgical, pathological and immunophenotypic findings are described. COX-2 imunohistochemical score was higher in hepatic metastasis (score 9) than in the primary tumour (score 6), and the growth fraction (Ki-67) observed was of $49.2 \%$ in the rectal neoplasm.
\end{abstract}

Keywords: enteric neoplasm, COX-2, oncology, carcinomatosis, metastasis

\section{RESUMO}

Carcinomas intestinais são raros em cães. O prognóstico e a sobrevida são dependentes do tipo histológico, do grau de invasão nas camadas intestinais e da capacidade da neoformação primária em desenvolver metástases. Relata-se um caso de um cão, da raça Yorkshire, que desenvolveu adenocarcinoma tubulopapilar retal com evolução para carcinomatose peritoneal e múltiplos focos metastáticos no intestino grosso, na bexiga, no rim linfonodo ilíaco, no fígado e nos pulmões seis meses após ressecção cirúrgica da neoplasia primária. Aspectos clínicos, cirúrgicos, anatomopatológicos e imunofenotípicos são descritos. O escore de COX-2 na imuno-histoquímica foi maior na metástase hepática (escore 9) do que na massa primária (escore 6), e a fração de crescimento (Ki-67) na neoplasia retal foi de $49,2 \%$.

Palavras-chave: neoplasia intestinal, COX-2, oncologia, carcinomatose, metástase

\section{INTRODUCTION}

Intestinal epithelial neoplasms in dogs are rare and represent less than $1 \%$ of the general findings from necropsies and biopsies (Patnaik et al., 1977; Head et al., 2002). Intestinal carcinomas usually occur in male dogs with an average age of nine years, without any breed predisposition (Patnaik et al., 1977; Church et al., 1987; Head et al., 2002; Paoloni et al., 2002). Rectal tumours may cause prolapse and are clinically associated with progressive weight loss, anorexia, presence of mucous and blood in feces and, in some cases, constipation (Head et al., 2002; Paoloni et al., 2002).

Colorectal carcinomas are classified, according to histological type, as simple adenocarcinoma (papillary, tubular and tubulopapillary), mucinous adenocarcinoma, signet ring cell carcinoma and undifferentiated or solid carcinoma (Head et al., 2002; Selting, 2013). In

Recebido em 15 de outubro de 2016

Aceito em 24 de maio de 2017

E-mail: ayisa.rodrigues@gmail.com 
gross morphology, the tumours may be solitary or multiple; intramural or intraluminal; with pedunculated, "cobblestone-like", polypoids, ringed or diffuse aspect (Head et al., 2002; Selting, 2013).

Clinical staging is related to prognosis and may drive therapeutic decisions, using the modified TNM classification. The animals are classified as stage I to IV depending on the affected histological layers $(\mathrm{T})$, the presence of lymph node metastasis $(\mathrm{N})$ and presence of distant metastasis (M) (Head et al., 2002).

The sparse number of reports contributes to the difficulty on predicting the biological behaviour of canine intestinal carcinomas (Head et al., 2002; Selting, 2013). This study aims to report a case of a Yorkshire dog, which has developed a metastatic tubulopapillary rectal adenocarcinoma after surgical resection of the primary tumour, emphasizing the clinical, surgical, pathological and immunophenotypical aspects during the disease progression.

\section{CASUISTRY}

A male Yorkshire dog, 13 years old, with $4.8 \mathrm{~kg}$, was presented with a history of persistent dyschezia and hematochezia for 12 months evolving to diarrhea in small amounts for several times a day associated with hematochezia. Physical exam revealed rectal prolapse and a polypoid protuberance in the middle third of the rectum (Figure 1).

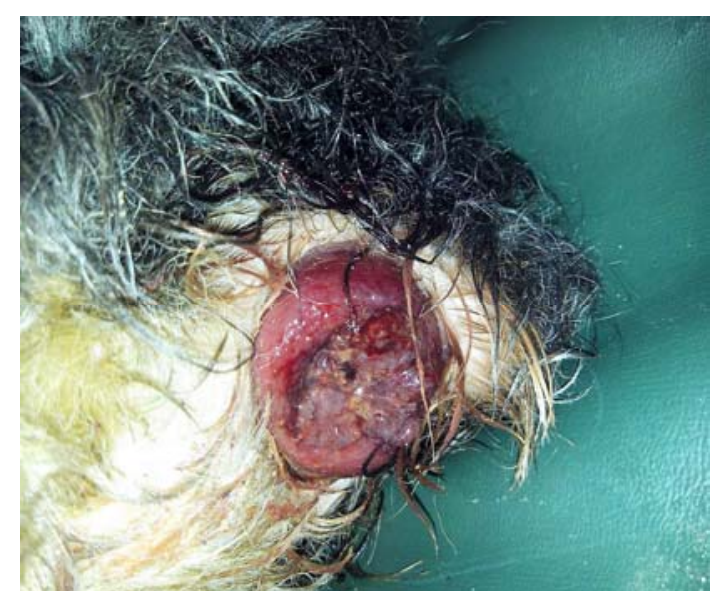

Figure 1. Yorkshire dog at physical examination with a rectal prolapse and a polypoid protuberance in the rectum.
Complete blood count showed a normocytic normochromic anaemia associated with neutrophilic leukocytosis and discreet thrombocytosis. Fecal examination was negative for helminth eggs and protozoa oocysts. Ultrasonography examination (USG) identified a rectal mass without any increasing of regional lymph nodes (N0) or any signs of metastasis in abdominal organs. Lung metastasis $(>0.2 \mathrm{~cm})$ were also absent in radiographic examination (M0) which allowed the classification of patients in stage I (T2, N0, M0).

Cytology through fine needle aspiration of the polypoid prolapsed tumor showed a moderate amount of rounded to columnar epithelial cells, with moderate pleomorphism arranged in islets with high intercellular adhesiveness and increased nucleus: cytoplasm ratio. Nucleus was eccentric nucleus, round to oval with, dark staining chromatin and evident nucleolus. Discrete anisocytosis, nuclear pleomorphism, and moderate anisocytosis with rare mitotic figures were also observed. The cytological examination was compatible with a well differentiated carcinoma.

The resection of the mass was performed by a transanal approach of the rectum after positioning the animal in ventral decubitus, with pelvic region elevated. The rectum was everted by caudal pulling with the aid of anchorage sutures arranged cranially to the mucocutaneous junction and then in cardinal points, to provide a better visualization of the tumor. A $360^{\circ}$ incision of total thickness of the rectum was performed leaving part of the rectal wall, apparently healthy, connected to the anus. After resection of the mass and rectum the rectal suture in one layer was performed, with polyglactin wire (910 3-0), applying sutures in simple separate standard throughout of the defect extension. The fragment of excised rectal was fixed in buffered formaldehyde solution $10 \%$ and submitted to routine histological processing and staining with hematoxylin and eosin (HE).

Grossly, the intestine had a thickened wall. The cut surface of the intestine wall was solid, whitish and firm. Mucosa showed an irregular surface, vegetating and projecting into the lumen (polyp). In the histopathological analysis, an epithelial neoformation predominantly disposed in tubules and papilla forming arboriform 
projections into the lumen (Figure 2a.) was noted, extending to the mucosa, submucosa and muscularis propria (T2) and composed of pleomorphic epithelial cells predominantly columnar with an increased nucleus: cytoplasm ratio. In deeper regions, the cytoplasm tended to be eosinophic, but in the superficial areas it was predominantly basophilic. There was little distinction between intercellular boundaries. The nucleus was basal, sometimes with loss of polarization, round to oval, with granular chromatin and nucleoli predominantly double and evident. Anisocariosis, anisocytosis, nuclear and cellular pleomorphism varied with the

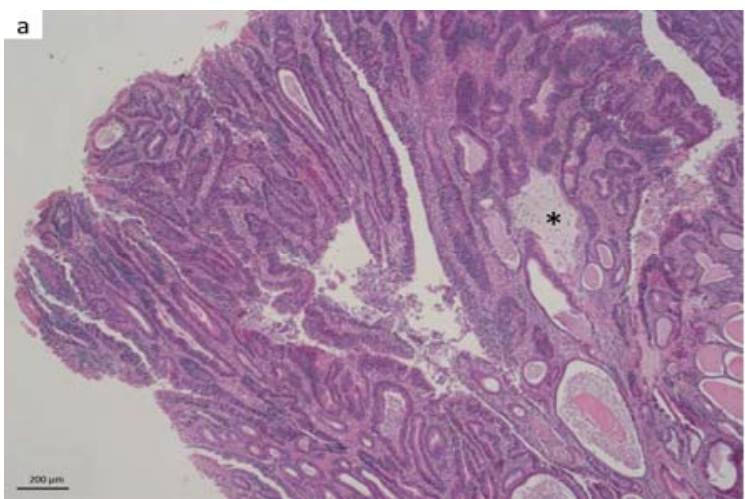

affected layers, being discrete in the mucosa, but evident into the muscle tunic. The same happened to the mitotic figures, rare on the surface but up to 20 mitotic figures in 10 high power field (HPF) in deeper regions of the neoformation. Some goblet cells had hyperchromatic and eccentric nucleus with signet ring appearance. In some areas, the intraluminal mucinous material was found between the tubules forming large lakes (Figure 2b). Some cuts showed extensive focus of lymphocytes and abundant neutrophils in the submucosa. The histopathological features were consistent with a tubulopapillary adenocarcinoma.

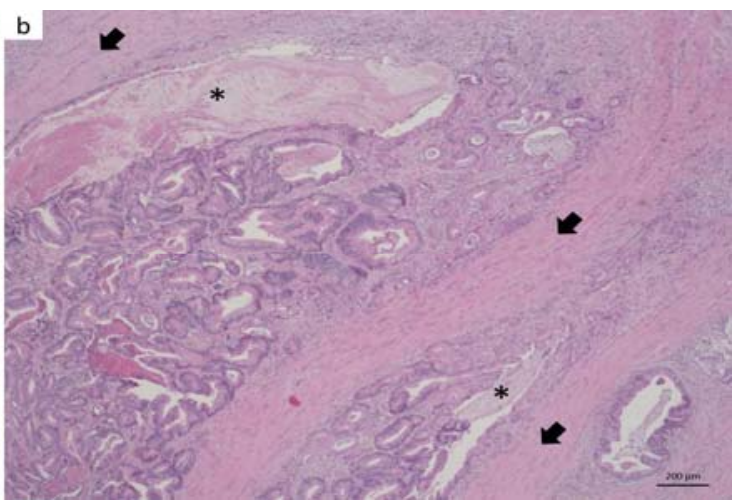

Figure 2. Yorkshire dog. a. Large intestine, polyp. Intraluminal projection consisting of tubulopapillary neoformation sometimes with ectasia and moderate amount of eosinophilic amorphous material and cellular debris in tubules; multifocal mucin lakes $\left(^{*}\right)$. HE, 50x. b. Large intestine, muscle tunic. Neoformation larded in muscle fibers (arrow). The tubular pattern is maintained with intraluminal mucin (*). HE, 50x.

After resection of the affected rectum, there was clinical improvement and the owners decided not to perform any adjuvant treatments. However, after six months, the animal returned to the hospital presenting with shivers, anorexia, weakness, yellowing catarrhal diarrhea in small quantities and oliguria. Blood count, creatinine and urea were normal. The abdomen USG revealed a right unilateral hydronephrosis with partial stenosis of the right ureter by a mass attached to the peritoneum and increased of the iliac lymph node (measuring $2.0 \mathrm{~cm} \times 1.0 \mathrm{~cm}$ ). Radiographic examination of the chest did not show any evidence of pulmonary macro metastasis $(>0.2 \mathrm{~cm})$.

Unilateral nephrectomy and removal of iliac lymph node were chosen. Histopathology found metastasis of colorectal adenocarcinoma (Figure 3 ) in both organs. Plenty neoplastic emboli was observed in lymphatic and blood vessels of renal serous and parenchyma. After surgery, the animal evolved to peritonitis and sepsis resulting in death.

At necropsy, a yellow, triangular, focally extensive area at the border of the liver was observed, with $2.0 \mathrm{~cm} \times 1.5 \mathrm{~cm}$ in its largest axis with multiple hemorrhagic foci, firm and characterized histopathologically by the same pattern observed in the lymph node, associated with large areas of necrosis and small areas of remaining liver parenchyma in the margin. In the abdominal cavity, besides a severe peritonitis and fibrinous adhesion of viscera, there were multiple nodules of 0.5 to $1.0 \mathrm{~cm}$ (carcinomatosis), forming a retroperitoneal mass of $5.0 \mathrm{~cm} \times 2.0 \mathrm{~cm} \times 0.6 \mathrm{~cm}$, soft, yellowish with hemorrhagic areas intermingled to fatty tissue located in the same area of nephrectomy. 


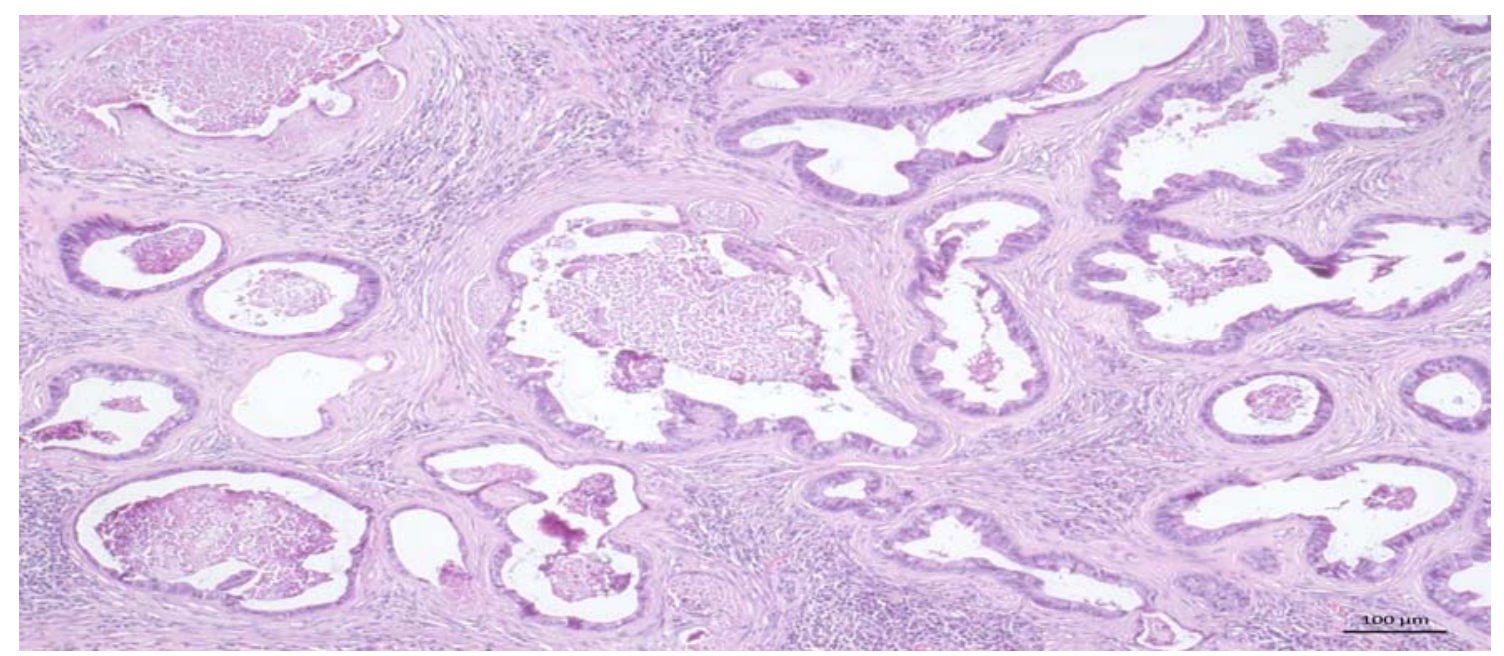

Figure 3. Yorkshire dog. Iliac lymph node. Metastatic tubulopapillary adenocarcinoma replacing much of the lymph node parenchyma, with basophilic amorphous material (mucin) associated with neutrophilic infiltrate and cellular debris, similar to the primary neoformation. HE, 100x.

Microscopically, rectal adenocarcinoma metastasis were observed in muscle and serosa of the bladder, large intestine and into the lung parenchyma. In all of these organs, there was a large quantity of neoplastic emboli in lymphatic and blood vessels. Lungs had multiple thrombi associated with neoplastic emboli, sometimes filling the entire lumen of the vessels.

Immunohistochemistry was used to identify the cyclooxygenase-2 (COX-2) expression (1:10 dilution; COX2-Clone SP21®; rabbit monoclonal antibody; NeoMarkers - Lab Vision Corporation, USA) in sections of $4 \mu \mathrm{m}$ of neoplastic rectal samples (primary tumour), liver and iliac lymph node, and Ki-67 expression (1:25 dilution; Ki-67 Antigen - Clone MIB-1®; monoclonal mouse anti-human; Dako, USA) only in primary tumour. The number of positive cells for COX-2 was estimated semiquantitatively and defined by estimating the percentage of positive cells according to their coloring intensity on a scale of 0 (no color) to 12 (strong staining) (Lavalle et al., 2009). The growth fraction was obtained by positive core count for Ki-67 in 500 neoplastic cells in "hotspots" HPF. The results are illustrated on Table 1 and Figure 4.

Table 1. Immunohistochemistry results for COX-2 and Ki-67 expression in primary tumour and for COX2 expression in iliac lymph node and liver metastasis

\begin{tabular}{cccc|}
\hline \multicolumn{2}{c}{ Primary Tumour } & Iliac lymph node & Liver \\
\hline Ki-67 & COX-2 ${ }^{2}$ & COX-2 ${ }^{2}$ & COX-2 ${ }^{2}$ \\
\hline $49,2 \%$ & Scale 6 & Scale 6 & Scale 9 \\
\hline
\end{tabular}

${ }^{1} \mathrm{Ki}-67$ values were obtained from positive core count for Ki-67 in 500 neoplastic cells in "hot-spots" HPF. ${ }^{2} \mathrm{COX}-2$ scales were defined by estimating the percentage of positive cells according to their coloring intensity on a scale of 0 (no color) to 12 (strong staining).

\section{DISCUSSION}

The dog of this report was within the age and gender most affected by intestinal carcinoma (Patnaik et al., 1977; Church et al., 1987; Head et al., 2002; Morello et al., 2008). The clinical signs such as dyschezia, hematochezia and rectal prolapse are also commonly associated with rectal neoformation (Head et al., 2002; Morello et al., 2008; Selting, 2013). Nevertheless, the period of manifestation of clinical signs, 12 months, observed in this case was higher than the 12 weeks described by Patnaik et al. (1977), but is within the period observed by Morello et al. (2008), that reported animals with clinical signs for more than 24 months before the first veterinary consult. 


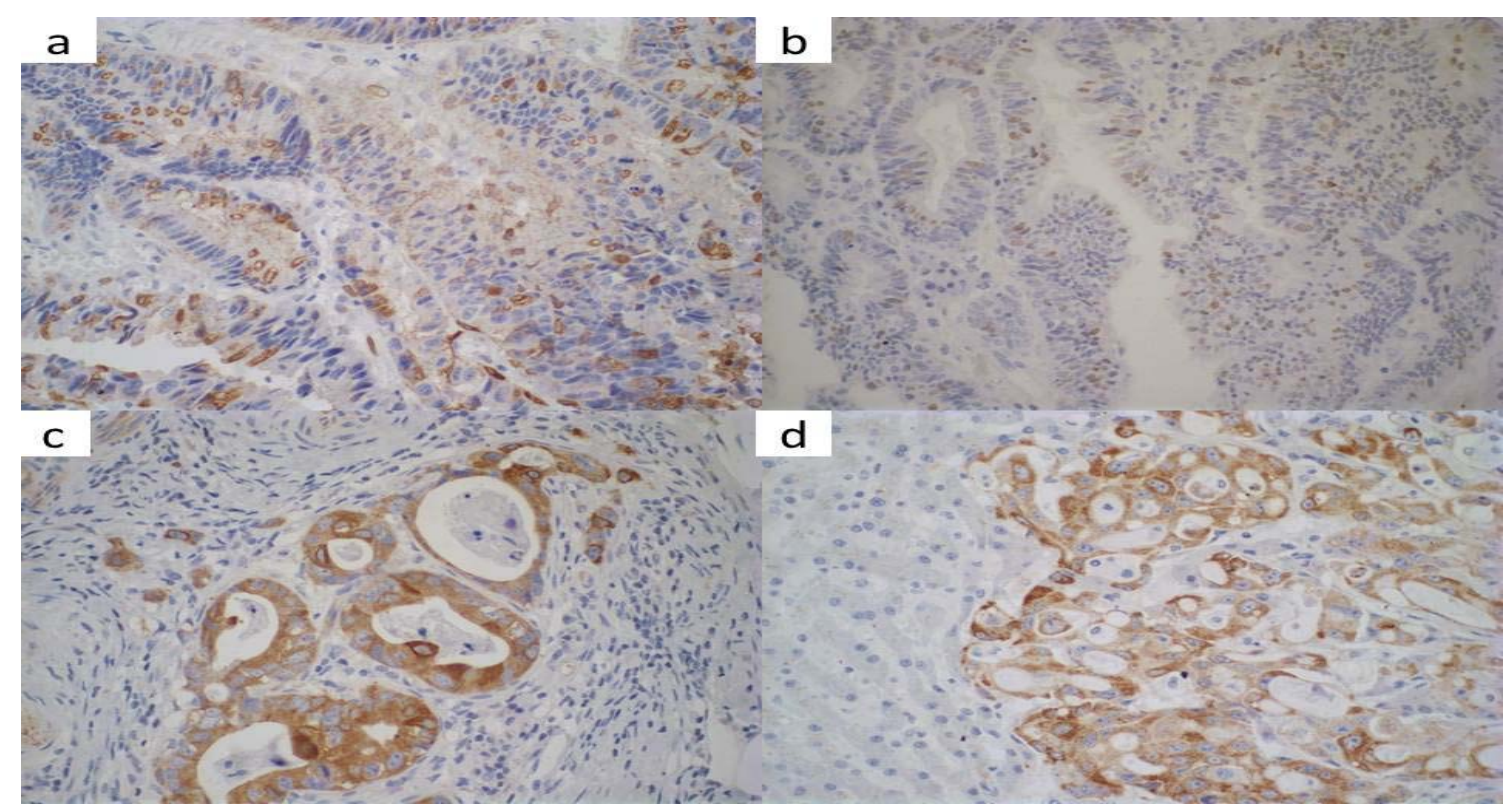

Figure 4. Yorkshire dog. a) Large intestine/ Primary tumor. Positive immunostaining for COX-2 (scale 6). 400x. b) Large intestine/ Primary tumor. Positive immunostaining for Ki-67 (49.2\% growth fraction). 100x c) Iliac lymph node. Positive immunostaining for COX-2 (scale 6). d) Liver. Positive immunostaining for COX-2 (scale 9).

Grossly, the diffused and ringed aspects tend to higher malignancy, predisposing patients to carcinomatosis (Head et al., 2002) and lower survival rates than other standards (Patnaik et al., 1977). The polypoid intraluminal standard tends to have benign characteristics (Head et al., 2002). The rectal tumor from this report presented a diffuse intramural aspect with intraluminal polyps. The colorectal polyps, as in this dog, are predominantly tubulopapillary, involving the mucosa and intestinal crypts. They can invade the submucosa and have marked atypia, developing malignant characteristics, constituting an adenocarcinoma (Head et al., 2002).

Although invasive (T2), the adenocarcinoma of this case was treated only by surgery. Chemotherapy has questionable benefit in such cases, since both neoplastic and normal intestinal cells express large concentrations of Pglycoprotein, which is directly related to resistance to anti-neoplastic drugs (Ginn, 1996). However, no studies in dogs have really confirmed or denied the benefit of adjuvant chemotherapy in intestinal cancer (Selting, 2013).
Animals with intestinal adenocarcinomas that had surgery for rectal amputation through transanal approach had a local recurrence rate of $18.2 \%$ with no observation of postoperative metastasis for 14 months of clinical monitoring (Morello et al., 2008). Overall survival, after surgery, ranges from 22 to 44 months (Church et al., 1987; Morello et al., 2008). However, in this report, with the same surgical approach, there was peritoneal carcinomatosis and multiple metastatic foci in various organs within six months. The animal of this study, in a stage I disease (T2, N0, M0), showed the same evolution documented in animals with T3N1M0 staging (Morello et al., 2008) and shorter survival time than cases not treated surgically (Patnaik et al., 1977; Church et al., 1987; Selting, 2013).The poor prognosis and shorter survival time found in this case, in comparison to the average, may be related to the long period between the onset of clinical signs and the surgical procedure, and also to individual, histological and immunophenotypical aspects of the tumor itself. Increased numbers of mitotic figures, in deeper layers of the primary tumor, was correlated to $\mathrm{Ki}-67$ immunoexpression, as expected. Intestinal carcinoma tends to become more malignant and invasive with time and local inflammatory stimulus (Head et al., 2002), which 
in this case could have led to an increase of affected layers (until the muscle tunica), but also to an increased capability to develop metastasis, which can be evidenced by increased COX-2 expression in metastatic foci, especially in the liver when compared to the primary mass (Cunha et al., 2016).

Cyclooxygenase-2 (COX-2) is an enzyme induced by growth factors, inflammatory responses, oncogenes and tumor promoters (Doré, 2011). In the dog, increases of COX-2 expression has been observed in tumors of various origins (Doré, 2011), including intestinal neoplasm (McEntee et al., 2002). In epithelial tumors it can be an effective tool for prognosis establishing (Cunha et al., 2016), and as a predictive factor for the use of selective COX-2 inhibitors in adjuvant treatments (Lavalle et al., 2009; Cunha et al., 2016). The high expression of COX-2 documented in metastatic cells of this cancer indicates that such treatment could be interesting in this case.

Peritoneal carcinomatosis and metastasis in regional lymph nodes are observed in some cases of rectal adenocarcinomas after surgery, but metastasis in liver, kidneys and lungs are uncommon (Head et al., 2002). In this case, the lung metastasis was not detected in routine radiographic examination and not on lung macroscopic examination, being identified only in post mortem microscopy. This suggests a greater difficulty in identifying this metastasis ante- mortem, even by more detailed imaging techniques such as computed tomography, making it necessary to use more invasive techniques such as lung biopsy. The few reports of lung metastasis in dogs may indicate the possibility of under-diagnosis associated with lack of reports of this neoplasm in dogs. In humans with colorectal adenocarcinomas, liver and lungs are the most frequent organs for metastasis (Shah et al, 2006).

\section{CONCLUSION}

A tubulopapillary rectal adenocarcinoma, diffuse and polypoid presented an aggressive evolution to peritoneal carcinomatosis and metastasis in large intestine, liver, bladder, kidney, and lungs. The invasive and metastatic behaviour was associated with the rise of atypical cells, cell proliferation in the primary tumor and increased
COX-2 expression in metastasis indicating involvement of this enzyme in progression of this neoplasm.

\section{REFERENCES}

CHURCH, E.M.; MEHLHAFF, C.J.; PATNAIK, A.K. Colorectal adenocarcinoma in dogs: 78 cases (19731984). J. Am. Vet. Med. Assoc., v.191, p.727-730, 1987.

CUNHA, R.M.C.; HORTA, R.S.; LAVALLE, G.E.; ARAÚJO, R.B. Cyclooxygenase-2 expression in epitelial neoplasms and its relevance as a targeted therapy in dogs. Cienc. Rural, v.46, p.1050-1052, 2016.

DORÉ, M. Cyclooxygenase-2 expression in animal cancers. Vet. Pathol., v.48, p.254-265, 2011.

GINN, P.E. Immunohistochemical detection of Pglycoprotein in formalin-fixed and paraffin-embedded normal and neoplastic canine tissues. Vet. Pathol., v.33, p.533-541, 1996.

HEAD, K.W.; ELSE, R.W.; DUBIELZIG， R.R. Tumors of the alimentary tract. In: MEUTEN, D.J. (Ed.). Tumors in domestic animals. 4.ed. Iowa: Blackwell Publishing Company, 2002. p.401-481.

LAVALLE, G.E.; BERTAGNOLLI, A.C.; TAVARES, W.L.F.; CASSALI, G.D. COX-2 Expression in canine mammary carcinomas correlation with angiogenesis and overall survival. Vet. Pathol., v.46, p.1275-1280, 2009.

McENTEE, M.F.; CATES, J.M.; NEILSEN, N. Cyclooxygenase-2 expression in spontaneous intestinal neoplasia of domestic dogs. Vet. Pathol., v.39, p.428-436, 2002.

MORELLO, E.; MARTANO, M.; SQUASSINO, C. et al. Transanal pull-through rectal amputation for treatment of colorectal carcinoma in 11 dogs. Vet. Surg., v.37, p.420-426, 2008

PAOLONI, M.C.; PENNINCK, D.G.; MOORE, A.S. Ultrasonographic and clinicopathologic findings in 21 dogs with intestinal adenocarcinoma. Vet. Radiol. Ultrasound, v.43, p.562-567, 2002.

PATNAIK, A.K.; HURVITZ, A.I.; JOHNSON, G.F. Canine gastrointestinal neoplasm. Vet. Pathol., v.14, p.547-555, 1977.

SELTING, K.A. Intestinal tumors. In: WITHROW, S.J.; VAIL, D.M.; PAGE, R.L. Withrow \& Macewen's small animal clinical oncology. 5.ed. Missouri: Elsevier Saunders, 2013. p.412-423.

SHAH, S.A.; HADDAD, R.; AL-SUKHNI, W.; KIM, R.D. et al. Surgical resection of hepatic and pulmonary metastases from colorectal carcinoma. $J$. Am. Coll. Surg., v.202, p.468-475, 2006. 